\title{
Beyond Progressive Liberalism and Cultural Relativism: Towards Critical Postmodernist, Sociohistorically Situated Perspectives in Classroom Studies
}

\author{
Angel Lin, City University of Hong Kong \\ Jasmine Luk, Hong Kong Institute of Education \\ In: Canadian Modern Language Review, (December 2002), 59(1), pp. 97-124.
}

\begin{abstract}
In this paper we propose that classroom studies in the TESOL field tend to subscribe to either of the following two normative orders, (1) progressive liberalism, and (2) cultural relativism, without reflexively recognizing and meta-analysing these normative frameworks and their social, historical and political situatedness. Drawing on Foucault's (1981) methods of historical excavation, we attempt a critical analysis of the sociohistorical situatedness of these modernist normative orders. By building on relational analysis from critical educational studies (Apple, 1999), critical ethnography (Canagarajah, 1993; Chick, 1996; Kumaravadivelu, 1999; Pennycook, 2001), and the theory and method of articulation from cultural studies (Slack, 1996), we propose critical postmodernist, sociohistorically situated perspectives in classroom studies and educational research as alternatives that break away from the modernist determinism of reproduction theories on the one hand, and radical postmodernist relativism on the other. We illustrate how such perspectives can contribute to our understanding of classroom practices with two classroom examples from Hong Kong schools, and we attempt to show the potential of these perspectives for contributing to the opening up of possibilities for change.
\end{abstract}

\section{Introduction: Classroom Studies and Their Implicit Normative Frameworks}

For any study there is the question of why study, why communicate the findings (and why listen and why read). This question becomes salient because of the more general (and philosophical, ideological) question of how one should live or what counts as the "good" life (Heap, 1990), or in our case, what people (or students, teachers, parents, principals, language education planners and policy makers) should desire to achieve in a language classroom or school, and how people should act in order to achieve the desired outcomes. While the "how" questions can be addressed, albeit often only partially, by research (i.e., systematic inquiry) and practical experience, the "what" questions cannot be answered without appealing to some normative orders or ideologies, often implicit, unspoken, and under-analysed, taken pre-reflectively as part of our common sense, or as part of the taken-for-granted canons of the educational, TESOL or applied linguistic disciplines. 
In this article, we want to do a critical meta-analysis of these implicit normative orders (or sociopolitical visions) underlying classroom studies in TESOL and applied linguistics. We want to foreground what has often been backgrounded (and under-analysed) in many classroom studies - their underlying normative frameworks, and in doing so, we want to show that the way we do our research is always already deeply ideological and political (Pennycook, 2001) and how by explicitly recognizing and analyzing such sociopolitical and sociocultural embeddedness we can reflexively engage with the ethical responsibilities inherent in doing educational research (ibid).

"Writing exists in the context of an implicit guiding metaphor that shapes the narrative" (Richardson, 1997, p. 17). We propose that research studies also exist in the context of guiding normative (or ideological) frameworks. These normative frameworks or storylines represent how groups of people (or researchers) tend to see the world and interpret and relate events to people and their actions. Instead of talking about normative frameworks or storylines as "right" or "wrong", one talks about normative frameworks or storylines in terms of the meanings, values that people (or researchers) give, often pre- or un-reflectively, to different events/actions/outcomes in the world, the visions (or teleos) that people have for themselves and others in relation to the world, and the subsequent sets of interpretations and recommendations based on studies done in their (often implicit) normative frameworks and then delivered to the educational community and the society at large (e.g., teachers, students, other researchers, policy makers, the public).

In Section 2 below, we shall attempt a critical analysis of two normative frameworks underlying many classroom studies in TESOL and applied linguistics: (1) progressive liberalism, and (2) cultural relativism. Despite their apparent differences, we shall see that they are more alike than disparate, both sharing modernist assumptions of essentialism and a lack of sociohistorical perspectives. This leads to a discussion of the emergent movement towards critical ethnographic studies as well as the deterministic limitation of critical reproduction theories. In Section 3, we draw on the theory and method of articulation from cultural studies (Slack, 1996) and propose a critical, non-deterministic approach to classroom studies. In Section 4, we illustrate the approach with two examples from Hong Kong schools, attempting to show the potential of the approach for contributing to our understanding of the sociohistorical situatedness of classroom practices and the opening up of possibilities for change. Section 5 concludes with a tentative proposal of future theoretical directions for classroom and educational research. 


\section{Progressive Liberalism, Cultural Relativism and Critical Perspectives}

Few in the educational field can question the profound influence of American philosopher and social, education reformer John Dewey, his progressive liberal education philosophy and his educational experiments in the Laboratory Schools associated with the University of Chicago in the early twentieth century. While current language education and TESOL theorists and researchers might or might not have explicitly recognized it, current pedagogical prescriptions or recommendations in the disciplines and in many teacher education courses do not seem to have gone too far beyond the progressive liberal educational principles that Dewey proposed almost three quarters of a century ago:

If one attempts to formulate the philosophy of education implicit in the practices of the new education, we may, I think, discover certain common principles amid the variety of progressive schools now existing. To imposition from above is opposed expression and cultivation of individuality; to external discipline is opposed free activity; to learning from texts and teachers, learning through experience; to acquisition of isolated skills and techniques by drill, is opposed acquisition of them as means of attaining ends which make direct vital appeal; to preparation for a more or less remote future is opposed making the most of the opportunities of present life; to static aims and materials is opposed acquaintance with a changing world. (Dewey, 1938, pp. 19-20; italics added)

From the outset, Dewey's education and school reform project is intimately connected with his social and political visions as the American society was witnessing a transformation from an agriculture-based, religious, authoritarian sociopolitical order to an industry- and commerce-based, secular, liberal sociopolitical order. To Dewey, education is instrumental in achieving a progressive democratic society where citizens, having been cultivated by progressive liberal education, are capable of actively and responsibly participating in the development and establishment of a progressive democratic order. Under such a political order, citizens engage in logical, systematic argumentation and empirical inquiry and problem-solving activities, in active, individual thinking based on empirical research rather than passive, massive subscription to authoritarian teachings whether religious or traditional, in self-expression and development of individual self-potential rather than mindless repetition of traditional doctrines, in creative, collaborative adaptations and explorations of new means to meet with new changes and difficulties in the world rather than irrational clinging to old methods and practices. Individualism, 
liberalism, empiricism, secularism and pragmatism might roughly sum up Dewey's progressive liberal educational principles and his social and political visions.

One might be surprised to find that many of today's Euro-and Anglo-based pedagogical recommendations do not seem to have gone far beyond the normative order outlined above, for instance, whole language approaches, communicative language teaching approaches, experience-based approaches, creative, learner-centred, meaning-based approaches and task-based approaches, although these broadly liberally oriented pedagogies have also come under increasing threats from recent neo-conservative movements; e.g., back-to-the basics, standardized testing and benchmarking. If occasionally, however, we hear remarks from teachers, especially those working in underprivileged, working class areas, that the pedagogical approaches recommended in the educational institutes are not feasible in their local working environments due to large class size, intensification of teachers' work, lack of resources, or uncooperative, unruly students, we might not be too surprised as from the outset the progressive education reform movement has been intertwined with and supported by middle class institutions and middle class material and cultural capitals since the early days of Dewey's experiment in the University of Chicago Laboratory Schools. According to Jackson (1990), the Schools seemed to serve what today would be called a middle-class clientele, which would include a number of children whose parents was on the faculty of the university:

It was, in short, a privileged environment. Dewey readily acknowledged this state of affairs and was quick to defend the school's special status. ... An experiment demands particularly favorable conditions... an unusually small teacher/pupil ratio, a dedicated and enthusiastic staff with time to reflect on what they were doing, well-behaved and eager students, an encouraging administrator, a supportive institutional environment, the backing of enthused parents, adequate materials and ample physical space - these well may be "needed resources" for the operation of an educational laboratory, as Dewey would have insisted, but they are also among the ingredients that contribute to educational excellence no matter where it is found. Such advantages may not in themselves guarantee a fine education but they certainly help to make it probable. (Jackson, 1990, pp. xxx-xxxii)

The above discussion allows us to understand the social, historical and political situatedness of progressive liberal pedagogies. From the outset progressive liberal 
pedagogies have been intertwined with and supported by middle class conditions and middle class capital, both material and sociocultural ones (Bourdieu, 1991). This, however, does not mean that progressive liberal pedagogies cannot be practiced, adapted or appropriated in working class conditions, and in fact many devoted education practitioners have strived to do this in under-resourced schools through their creative discursive agency to help their students to gain the linguistic capital to compete with their middle-class counterparts in the society (e.g., Teacher D in the study by Lin, 1999; see also discussion on the theory of articulation in Sections 3 and 4 below). Furthermore, the above historical analysis of the progressive liberal normative order is not meant to be a critique of that order per se, but rather as an attempt at an historical excavation, in Foucault's (1981) sense, of the social and historical situatedness of implicit, underlying ideologies (or sociopolitical visions) guiding many of our current educational and research practices. This is an attempt to understand the history of the present, and the sociohistorical and political embeddedness of present-day educational canons, so as to open up possibilities for seeing the present educational prescriptions or recommendations not as natural, neutral outcomes of purely scientific discovery of universal, essential truths about human functioning and development, but as equally socially and historically conditioned as traditional, non-progressive educational canons are.

The above discussion brings us to a consideration of cultural relativism, an equally pervasive modernist normative order underlying many classroom studies in TESOL, especially those conducted in non-Western sociocultural settings. If progressive liberalism as an implicit normative order guiding educational practice and research has derived its authority from its claims of scientific, universal, essential truths about human functioning and development, cultural relativism has derived its authority from claims about essential differences in cultures, genders, classes, and so forth (Gould, 2001). While progressive liberalism and cultural relativism seem to be opposed to each other, they both share an essentialist, reified, non-sociohistorical view of human functioning, development and cultures. As such, they are both products of modernism, which has us believe in totalized grand narratives, whether they are about human nature or specific cultures. While progressive liberalism would have us believe in a universal human nature and human developmental path, cultural relativism would have us believe in internally more or less static, homogeneous cultures each with a disparate set of essential features. Cultural relativism tends to gloss over the local, situated struggles of marginalized peoples (e.g., women, minorities, disadvantaged social groups) within a culture by absolutizing and naturalizing the values and practices of dominant groups as well as relations of 
dominance and subordination in a culture (i.e., the status quo), and by reifying boundaries between cultures (Li, 1995). Ryuko Kubota (2001) has, for instance, problematized the dichotic, essentialist constructions of images of Western and non-Western classrooms in the TESOL and applied linguistic literature and pointed out the internal diversity within both Western and non-Western classrooms (e.g., there are teacher-fronted classrooms in the U.S., and there are liberal, egalitarian classrooms in non-U.S. contexts). Kubota, citing Said (1978), went on to excavate the colonial origins of such essentialized, dichotomous constructions of Self and Other. From the above historical analysis, we can see that both progressive liberalism and cultural relativism have arisen from particular sociohistorical conditions and as (often implicit) normative orders guiding educational practice and research, they are in serious need of a critical reflexive analysis of their own sociohistorical situatedness.

However, modernist ideologies (i.e., normative orders) are typically non-sociohistorically reflexive precisely because they derive their authority by abstracting and universalizing their claims from the specific sociohistorical conditions that gave rise to them in the first place, and thereby denying their ideological, particular nature through posing as scientific, universal truths. Many TESOL classroom studies have suffered from such a limitation. Typically, findings based on classroom studies situated in a specific sociohistorical context (e.g., SLA studies in U.S. university ESL classrooms) are abstracted from the context of the studies and asserted as (working approximations of) universal truths about human language acquisition. These abstracted universal knowledge claims are especially common in the TESOL literature.

The field of language and literacy education outside of the mainstream TESOL literature has, however, witnessed the rising importance of socioculturally situated ethnographic classroom studies (e.g., O’Connor and Michaels, 1996; Moll and Dworin, 1996; Collins, 1996) as well as an emergent movement towards critical classroom studies (e.g., Kumaravadivelu, 1999; Heller and Martin-Jones, 2001; Block and Cameron, 2002). In this area, Rampton (1995a, 1995b) has done important pioneering work in articulating applied linguistics, sociolinguistics and cultural studies, and in arguing for a critical applied linguistics (see also Pennycook, 2001). This emergent movement from doing micro-ethnographic classroom studies towards further situating these studies in their larger sociohistorical and political contexts can best be exemplified in classroom ethnorapher Keith Chick's research and analytic journey. Chick's (1996) classical study of "safe talk: collusion in apartheid education", cited in Kumaravadivelu (1999) as an example of critical classroom 
discourse study, illustrates well an ethnographic classroom researcher's journey of critically, reflexively deconstructing the implicit normative orders (first, progressive liberal pedagogy; then, cultural relativism) that have guided his earlier interpretations of his ethnographic classroom findings:

To begin with, I report on my micro-ethnographic analysis of an episode in a lesson in a KwaZulu classroom. ... My specific purpose was to try to establish why teachers and students in such classrooms found it difficult to transfer to styles compatible with communicative language teaching. The analysis reveals interactional behaviour consistent with the putative Zulu-English interactional styles identified in the interethnic encounters referred to above. More significantly, it reveals that such styles served valuable social functions for students and teachers alike. This could account for why teachers and students were reluctant to abandon such styles, despite that fact that the academic consequences of such preference were probably unfortunate. I then explain how my growing awareness of the limitations of micro-ethnographic research in general, and explanations of pervasive school failure amongst dominated groups in terms of culturally-specific interactional styles in particular, prompted me to re-examine my classroom interactional data. Critics have pointed out that micro-ethnographic studies often take insufficient account of how pervasive values, ideologies and structures in the wider society (macro context) constrain what takes place at a micro level. ...

... I was, therefore, open to the suggestion that a limitation of my original analysis of the episode was that I had not adequately contextualized my data; that I had not taken sufficient account of the effect on classroom discourse of such factors as the differential funding of the racially segregated school systems, differential teacher-student ratios, levels of teacher training and so on. (Chick, 1996, pp. 24-31; italics added)

By re-considering the larger institutional, social, economic and political contexts in which the classroom practices (i.e., non-communicative, teacher-fronted, whole class choral responses) that he observed were situated (i.e., conducting a relational analysis as also delineated in Apple, 1999), Keith Chick offered a critical re-analysis and re-interpretation of his findings, showing the relations of dominance and subordination as well as the local agency and resistance of the KwaZulu teachers and students when they engaged in the specific interactional practices that Chick characterized as "safetalk", talk that creates a space where teacher and students know more or less what to expect and how to behave in class, but where a high price is paid 
in terms of (a lack of) learning. Chick interprets their practices "as a means of avoiding the oppressive and demeaning effects of apartheid ideology and structures, ... as colluding in preserving their dignity by hiding the fact that little learning is taking place." (Chick, 1996, p. 24).

Keith Chick did also stress the mixed consequences of their resistance practices:

While serving the short-term interests of teachers and students, such strategies, I suggest, contributed to the widely documented high failure rate in black education in apartheid South Africa, and made teachers and students resistant to educational innovation. The strategies thus served to reinforce and reproduce the inequalities between the various population groups which characterized apartheid society. (Chick, 1996, p. 24)

Keith Chick's critical ethnographic classroom study along with other similarly critical ethnographic classroom studies (e.g., Lin, 1996) that have been, in one way or another, guided by Bourdieu's reproduction framework, while having succeeded in uncovering the relations of dominance and subordination and the mechanisms of reproduction of social inequalities in specific sociopolitical contexts, however, run the risk of emphasizing too much the reproduction side, and showing little of the possibilities for transformation and change, and hence offering pessimistic, deterministic views, as noted by Canagarajah (1993, 1999) and Pennycook (2001). Allan Luke (2002a, 2002b) also argued that we need critical studies that do not merely deconstruct and critique ideologies but also show the productive uses of power and discourse in new conditions. It is against this background that we shall turn to the theory and method of articulation from cultural studies in the next section to look for conceptual and analytic tools that might enable us to study not only reproduction but also to engage with possibilities for local, situated change and transformation.

\section{The Theory and Method of Articulation}

In cultural studies, articulation means the joining together or conjuncture of different social, institutional, technical, economic and political forces. Jennifer Slack gave an introduction to the theory and method of articulation in her article collected in David Morley and Kuan-Hsing Chen's (1996) edited volume entitled "Stuart Hall: Critical dialogues in cultural studies". The following is a summary of Slack's (1996) delineation:

By the 1970s, cultural theorists were engaged in critiques of the economic reductionism and class reductionism of classical or orthodox Marxism. Briefly put, economic reductionism maintains that economic relations (the base) control 
and produce (determine) everything else in society (the superstructure), whereas class reductionism holds that all political and ideological practices, in short all that might be conceived of as other than economic, have a necessary class belonging which is defined by the mode of production. Struggling to substitute reduction and re-theorize processes of determination, a theoretical space develops and gets filled with terms like 'productive matrix' and 'combination of relations', and eventually 'articulation'. Drawing on Marx's conception of a social formation as a combination of relations, within which determination must be understood as produced within specific conjunctures rather than as produced uniformly and directly by the mode of production, the conjunctures come to be seen as historically specific articulations of concrete social forces (see Hall, 1977).

Stuart Hall's contributions to the development of articulation have been significant for a number of reasons. First, he resists the temptation of reduction to class, mode of production, structure, as well as to culturalism's tendency to reduce culture to 'experience'. Second, he elevates the importance of articulating discourse to other social forces, without going 'over the brink' of turning everything into discourse. Third, Hall's commitment to the strategic feature of articulation has foregrounded cultural studies' interventionist commitments.

To Hall, interrogating any articulated structure or practice requires an examination of the ways in which the 'relatively autonomous' social, institutional, technical, economic and political forces are organized into unities that are effective and are relatively empowering or disempowering. Determining when, where and how these forces might be re-articulated is the aim of a cultural theorist's theoretically-informed political practice. The examination of and participation in any practice is thus an ongoing process of re-articulating contexts, that is, of examining and intervening in the changing ensemble of forces (or articulations) that create and maintain identities that have real concrete effects. "Understanding a practice involves," as Grossberg puts it, "theoretically and historically (re)-constructing its context" (Grossberg, 1992, p. 55).

(Summarized from Slack, 1996, pp. 116-125; italics added)

The theory and method of articulation as delineated above points to the possibility of avoiding pessimistic, deterministic or reductionist views found in some critical 
classroom studies. By highlighting the possibility of strategically re-constructing the context of classroom practices, critical classroom researchers can go beyond merely "studying" and "understanding" the classroom practices being observed, for "understanding a practice involves theoretically and historically (re)-constructing its context" (Grossberg, 1992, p. 55) to render it more empowering or less disempowering for the local participants involved. Stuart Hall sees his theoretically informed political practice as part of doing "Marxism without guarantees" (Hall, 1996), emphasizing the local, contingent, sociohistorically situated nature of critical, interventionist practices, with no success guaranteed (unlike classical Marxism). We may add that while there is no guarantee of success, there is no guarantee of failure, either, and hence there is the possibility of breaking away from pessimistic, deterministic, reproduction views. In the next section, we shall attempt to illustrate a critical, situated approach that is informed by the theory and method of articulation through contrasting two classroom examples from Hong Kong schools.

\section{Contrasting two classroom examples from Hong Kong schools}

\section{Example (1)}

\section{About the Teacher and the Researcher:}

The first example was taken from a Secondary Year One (similar to Grade 7 in the N. American system) English lesson. The teacher, Jennifer (pseudo name), a Welsh lady from Britain, had served as an expatriate English teacher (or Native English-speaking teacher, NET for short) in Hong Kong in the same school for more than four years at the time of the study in 1999. Jennifer's lessons were audio- and video-recorded as part of an ethnographic case study which was conducted as the second author's doctoral research with an initial focus on cross-cultural interactions between native English teachers and Cantonese students in English language classrooms in Hong Kong. Jennifer, introduced to the researcher through a friend, had agreed to participate in the study primarily to assist with the researcher's doctoral study. Jennifer was visited several times by the researcher during the academic year and lessons of two classes of hers were videotaped and observed. Ethnographic interviews were also conducted with Jennifer, samples of her students, and other teachers in the school.

Jennifer was mainly teaching lower secondary classes at the time of the study and this was out of her own preference. She felt that younger children seemed to be more receptive to the teaching of a NET as she felt they were more willing to experiment with the target language and under less pressure to study for the public examinations. However, Jennifer still found herself under constant pressure to cover the topics in the 
textbook because the standardized internal school tests and examinations were set around the assigned textbook topics which teachers of all classes at the same year level were required to teach. This is a common practice in the standardized-test-driven, curricular culture in Hong Kong schools.

Jennifer was interested in Cantonese, the daily life language of the majority of people in Hong Kong, and was learning Cantonese at the time of the study. She had a Bachelor of Education degree in Teaching German and French and a Royal Society of Arts Certificate from the British Council. Although Jennifer did not have a strong background in TESOL, she felt that her training and experience in teaching other modern languages were great assets in her present job because of her experience as a second language learner.

Jennifer was well aware of the current approaches recommended for English Language teaching such as the communicative approach and task-based learning. However, she felt that these approaches were very often difficult to implement in Hong Kong classrooms because of practical constraints. The first constraint was the large class size. With forty students crammed into a small classroom, it was difficult to conduct communicative activities with close monitoring of the teachers and an acceptable noise level. The second constraint came from what Jennifer saw as the much less pupil-centred education system in Hong Kong, compared to that in the UK. In Jennifer's words, "students are used to sitting there, listening. There are less teaching activities focusing on pupils' finding out knowledge for themselves". Jennifer thought that this kind of classroom culture was probably induced by the large class size which in turn has conditioned teachers to adopt a more teacher-fronted, one-way delivery mode.

Jennifer mentioned two elements in designing her favourite teaching activities. First, they should be fun; second, they should involve real use of the language. "I'd like to have a relaxed atmosphere. I'd like to encourage people to speak, to talk to me. The more they talk to me in English the happier I am," said Jennifer during the interview. However, everything still depends on the culture of the class. If some classes had become too hysterical and noisy during the lesson games, Jennifer admitted that she would stop the games and assign some traditional writing and reading work to the students. This had been done to 1A (the class that in Example 1), which Jennifer described as her headache class from Day 1. 


\section{About the School and the English Curriculum:}

The school is situated in a working class public housing estate in proximity to some luxurious private apartments. The majority of students had low SES backgrounds, but there were also a few students from more well-to-do families. One or two students in some of the classes were returnees from English-speaking countries. The returnee students' English in the school was good in general compared to many other local students in Hong Kong, but their attitude towards study, and/or their academic results in other subjects were not necessarily "good", according to the teachers of the school.

Like the majority of secondary schools in Hong Kong, the English curriculum in Jennifer's school was centred around a set of textbooks produced by local commercial publishers with topics oriented to local contexts. According to Jennifer, teachers in her school were under pressure from the parents to teach according to the textbooks and produce a lot of worksheets. There were cases when some parents complained to the Principal that the teachers had not taught anything because there were no marks on the textbooks, and their children were not learning anything because they did not have any worksheets to bring home.

\section{About the Class: 1A (20 boys and 21 girls)}

The lesson excerpt shown below is taken from the 1A class (Secondary One or Grade 7 in the N. American system). The class was among the first batch of students admitted after the school had lost her prestigious EMI (English medium instruction) status in 1998 when three-quarter of secondary schools in HK were "forced" by the Education Department to adopt Chinese as the medium of instruction at junior secondary level because their students' English standard was regarded as not up to the standard for English immersion (see Lin, 1996, 1997 for a background of the medium of instruction policy in Hong Kong). According to the teachers there, this had affected the quality and standards of their new student intakes. Class 1A was a regular class of 41 students, and Jennifer took all the English lessons of 1A. The classroom setting was a traditional one but typical in Hong Kong: with rows of desks crammed into a small classroom. The lessons are largely textbook-based, supplemented with worksheets, which is a typical practice especially in working class schools in Hong Kong (see Lin, 1999).

The following exchanges took place in the beginning part of a lesson. Jennifer was attempting some pre-reading elicitations with the class. The teacher was about to teach a textbook chapter titled "Eating out". The teacher $(\mathrm{T})$ began by revising the 
names of some food items found in fast-food restaurants in HK, as suggested by the textbook teacher's manual. Then the teacher prepared students (Ss) to read an e-mail letter from a girl called Candy about her birthday meal. In the e-mail letter, Candy wrote to her friend Sandy inviting her to join her birthday party to be held at the McDonald's. The following lesson excerpt shows the pre-reading preparation stage. Immediately after this stage, students were asked to read the e-mail on the textbook, followed by some questions on a few vocabulary items raised by the teacher. The students could give the meanings of all the items asked by the teacher in English, but they responded invariably in Cantonese. The students were extremely quiet during the subsequent silent reading of the email; however, during the pre-reading elicitation stage, they were very talkative, as can be seen in the transcript below:

\section{Notes on Transcription:}

\section{Symbols Meaning}

$\mathrm{T} \quad$ The teacher

$\mathrm{B} 1, \mathrm{~B} 2, \ldots \quad$ Indicates different boys in consecutive speaking turns; not necessarily referring to the same boys when B1, B2 appear later in the transcript

B An unidentifiable boy

Ss Many students

\{\}$\quad$ Brackets researcher's comments

(???) Indecipherable utterances

(.) Falling intonation followed by noticeable pause (as at the end of declarative sentences)

(..) Short pause

(...) Medium pause of up to five seconds

, Continuing intonation

? Rising intonation, may or may not be a question

$\wedge \quad$ Utterances at a high pitch

: $\quad$ Lengthened syllable (usually attached to the vowels); extra colon indicates longer elongation

Self-halting, or abrupt cutoff; also indicates linking of syllables in a word in the Cantonese transcription

CAPITALS Emphatic and strongly stressed utterances

$=\quad$ Indicates latching; also indicates a continuing utterance of the same speaker whose transcription has been interrupted by transcription of another simultaneous speaker's utterance

// Within each column, marks the point where different speakers' utterances start overlapping with each other 


\section{Other transcription information:}

1. The two columns of transcriptions show simultaneous interactions taking place, with the left-hand column recording mainstream interaction involving the teacher and the right-hand column capturing student self-initiated peer-talk which may or may not have been heard by the teacher.

2. Spoken Cantonese from the data was transcribed using the system of Cantonese transcription developed by the Linguistic Society of Hong Kong (1997). The transcribed Cantonese is marked by boldface (lower case) followed by italic English translations in pointed brackets. All personal names are replaced by pseudo names.

\begin{tabular}{|c|c|}
\hline $\begin{array}{l}\text { T: ... that is NOT, a soft drink. } \\
\text { T: So soft drink does NOT have alcohol, } \\
\text { alright? }\end{array}$ & $\begin{array}{l}\text { B1: }\{\text { asking his neighbour }\} \text { soft drink zikhai } \\
\text { me lai gaa? }<\text { What exactly is soft } \\
\text { drink?> }\end{array}$ \\
\hline $\begin{array}{l}\text { T: An alcoholic drink is beer, wine, things like } \\
\text { that, // soft drink, coke, lem onade= } \\
\text { B: // Jau-zau-zing jum-ban aa?< Alcoholic } \\
\text { drinks ?> } \\
\text { B: =Lemonade. }\end{array}$ & $\begin{array}{l}\text { B1: } \text { \{chuckling on hearing a Cantonese } \\
\text { utterance from another boy, indistinct on } \\
\text { the tape\} dung-jam aa? <cold drink?> } \\
\text { Dung-jam wo. <lt's cold drink.> } \\
\text { B2: Dung-jam aa. <It's cold drink.>, }\end{array}$ \\
\hline $\begin{array}{l}=\mathrm{T} \text { : tea, things like that, alright. Okay, how } \\
\text { many people here? (.) when they have a } \\
\text { birthday? (.)= } \\
\text { B: Go-go dou jau gaa-laa! <Everybody has } \\
\text { got it!> }\end{array}$ & $\begin{array}{l}\text { Wong Wai Kei }\{\text { a boy's name\}, nei mhou, } \\
\text { nei m-hou baan m-sik laa! } \\
<\text { Wong Wai Kei, don't pretend to be } \\
\text { ignorant!> }\end{array}$ \\
\hline $\begin{array}{l}=\mathrm{T} \text { : go to McDonald's, anybody? } \\
\text { T: In England, \{T pointing to a B when saying } \\
\text { the next sentence as if he had responded } \\
\text { positively. Many Ss laugh loudly, obviously } \\
\text { about some inside jokes they share. The T is }\end{array}$ & $\begin{array}{l}\text { B: Go-di dai-nang gaa! <Those are } \\
\text { mental retards!>, baak-ci gaa! <ldiots!> } \\
\text { \{clear on the audio tape but not captured } \\
\text { on the video tape as many Ss are talking } \\
\text { at the same time; the T probably did not } \\
\text { hear this comment.\} }\end{array}$ \\
\hline $\begin{array}{l}\text { smiling as if she shares the joke.\} YOU go to } \\
\text { McDonald's, (..) okay, in-, in England, when } \\
\text { little children go to McDonald's, they get the } \\
\text { balloon, you know what a balloon is? }\end{array}$ & $\begin{array}{l}\text { Ai-jaa! \{particle showing surprise\}, } \\
\text { baak-ci-zai aa ! <ldiots!> \{sounds like } \\
\text { talking to neighbours, with a normal peer } \\
\text { conversation volume\}, XXX }\{\text { somebody's } \\
\text { name, not clear on the tape\}, keoi waa } \\
\text { keoi heoi-guo wo! <He said he had } \\
\text { been there!> }\end{array}$ \\
\hline
\end{tabular}




\begin{tabular}{|c|c|}
\hline B: Hei kaau <balloon> & $\begin{array}{l}\text { \{Some Ss are chatting on their own } \\
\text { here, not clear on the tape.\} }\end{array}$ \\
\hline $\begin{array}{l}\text { T: They get a hat. \{many Ss laugh loudly\} } \\
\text { B: Balloon. }\end{array}$ & $\begin{array}{l}\text { B: }\{\text { captured on the videotape but not } \\
\text { the audiotape\} Heoi Mak-Dong-Nou } \\
\text { waan bungy-jump aa? <Go to McDonald's } \\
\text { to play bungee jump?> }\end{array}$ \\
\hline $\begin{array}{l}\text { T: And they get a little bag of toys // [(??? } \\
\text { ???) on their birthday, yeah? So (..) a lot of } \\
\text { children like, to go to McDonald's on their } \\
\text { birthday. Yes? But usually that's little children, } \\
\text { \{Ss laugh\} not big ones \{Ss laugh\}. Where do } \\
\text { you go on your birthday? }\end{array}$ & $\begin{array}{l}\text { B: \{captured by the recorder only\} Wong } \\
\text { Wai Kei }\{\text { a boy's name\}, nei m-hai } \\
\text { heoi-guo aa? <You haven't been there, } \\
\text { have you? }\end{array}$ \\
\hline $\begin{array}{l}\text { Ss: Home, //home, home! } \\
\text { T: //You stay at home? } \\
\text { Ss: Yes= } \\
\text { B: =NO! }\end{array}$ & \\
\hline $\begin{array}{l}\text { T: Who goes out on their birthday? Does } \\
\text { anyone go to the restaurant? }\end{array}$ & \\
\hline $\begin{array}{l}\text { B1: Hotel! } \\
\text { T: Or expensive hotel? }\end{array}$ & $\begin{array}{l}\text { B2: \{B1's neighbour, apparently responding } \\
\text { to B1's response\} Nei aa } \\
\text { soeng laa! < You're dreaming!> } \\
\text { \{speaking up again in his seat\} Nei aa } \\
\text { soeng laa! <You're dreaming!> } \\
\text { Hote::1!? \{said with a Cantonese accent, } \\
\text { stressing both syllables and with a tone } \\
\text { sounding as if B1's saying is incredible\} }\end{array}$ \\
\hline $\begin{array}{l}\text { T: You go to- (..) shh::, you go to the uhm (.) } \\
\text { Peninsula hotel? And have a meal for four } \\
\text { hundred dollars? (.) No? \{many Ss are talking } \\
\text { in Cantonese, and do not seem to be paying } \\
\text { attention to T\} Okay, have a look- (...) \{many } \\
\text { Ss are still talking\} }\end{array}$ & \\
\hline Some Ss: Shhshhshhshh! & \\
\hline $\begin{array}{l}\text { T: In your books^ (.) \{many Ss still talking\} } \\
\text { page seventeen, let's have a look at unit } \\
\text { eight, page seventeen. \{many Ss are still } \\
\text { talking\} } \\
\text { B: Seventeen. }\end{array}$ & \\
\hline
\end{tabular}




\section{Analysis and Discussion:}

A sequential analysis (Heap, 1997) of the teacher-student exchanges shows that the teacher seems to be trying to co-construct with her students an English corpus of utterances related to the topic of the passage that she was going to ask the class to read after this pre-reading preparation stage, by using the IRF (Initiation - Response Feedback) triadic discourse format to elicit specific text topic-related responses from students. Her questions revolved around first the vocabulary to be found in the text, then the topics to be covered in the text, e.g., going to the McDonald's for a birthday party. Two boys commented in Cantonese that those who go to the McDonald's on their birthdays are mental retards but the teacher apparently did not hear these remarks. She went on to try to get students to give her responses that she could use to build up a corpus of English utterances covering the topic of McDonald's for birthday parties. However, the students answered "home" when she asked them where they went on their birthdays. She apparently found this response not too useful for her purpose, not asking any follow-up questions on this response (e.g., she could have asked: What do you do at home on your birthday?). She pressed on by re-initiating another set of questions: Who goes out on their birthday? Does anyone go to the restaurant? A boy playfully said, "Hotel!", apparently not relaying a true experience as another boy immediately shouted out in Cantonese: <You are dreaming!>. The teacher went along with the joke for a while and then asked the students to look at page seventeen of the book, getting them to focus on the text.

The above micro interactional analysis shows us a picture of a teacher who is textbook-driven. Though she has attempted to create opportunities for students to express and share experiences, she tends to gloss over those that are not directly relevant to the textbook topic about having birthday party at McDonald's. The normative framework of progressive liberal pedagogies will probably lead us to arrive at a recommendation of "fixing" the teacher, especially given the explicit aims of the Hong Kong government in importing expensive, expatriate, native English teachers to improve the English expressive skills of Hong Kong students and to bring in innovative teaching practices. However, in Jennifer's words, "1A was a headache from Day One", even though the class appeared to be very clever to her. " $1 \mathrm{~A}$ is the quietest when they've got a grammar worksheet. They will keep their heads down and they'll be silent. Give them a game which they obviously enjoy more and all the 40s will speak at the same time. They don't put up their hands; one or two might; they prefer shouting out the answers," said Jennifer in an interview to the researcher. 
Alternatively, the normative framework of cultural relativism might have us conclude that the teacher was simply being culturally sensitive when she decided to adopt a teaching method that capitalized on the students' traditional learning style: they were attentive and on-task when they were given structured textbook exercises or grammar worksheets. Besides, there have been many ethnographic studies showing similar traditional learning styles of Chinese students.

However, if we draw on Apple's (1999) notion of relational analysis and Canagarajah's (1993) critical ethnography, analyzing the larger institutional, socioeconomic and sociocultural contexts in which these classroom participants are situated, we might arrive at somewhat different interpretations. The large class size (41 students) and the small, crowded, inflexible classroom setting obviously imposed practical constraints on the implementation of progressive liberal pedagogies, which have originally arisen from middle-class conditions and supported by middle-class capitals (see discussion in Section 2 above). Besides, expatriate teachers in Hong Kong are generally socioculturally isolated from the Cantonese-speaking communities. Although Jennifer was learning Cantonese at the British Council, her Cantonese proficiency was still quite rudimentary, and like many other expatriate teachers in Hong Kong, her social circles were likely to be within the expatriate community. This probably gave her an extra uneasy feeling when she often could not understand what the students were laughing and talking about in Cantonese when they were not quiet or answering textbook questions. The classroom observer, who understands both Cantonese and English, found that sometimes when the students were talking in Cantonese, they were either asking their neighbours about what the teacher was asking them to do, or were joking about topics that the teacher had initiated, as can be seen in a small way in the lesson excerpt shown above; e.g., ironically joking about going to the McDonald's to play "bungy jump", about mental retards going to the McDonald's on their birthdays-these could be seen as creative assertions of their indigenous views and identities. However, they were not particularly unruly, disrespectful or off-task, at least in the eyes of the bilingual researcher. The non-Cantonese-speaking native English teacher, nevertheless, had no way of differentiating between students being off-task or on-task. In want of a classroom management strategy amidst a classroom full of unintelligible noises, resorting to structured textbook exercises and grammar worksheets became apparently the most sensible strategy available to her despite her original belief in progressive liberal pedagogies (e.g., games that students will enjoy more). 
A particular historical conjuncture of different social, cultural, institutional, technical, economic and political forces has formed the ensemble of articulations that created and maintained the specific practices and identities that we witnessed in this classroom. These forces seem to be: a Hong Kong government that subscribes to the dominating, interested notion that native English speakers necessarily make better English teachers than non-native English speakers, a monolingual pedagogical prescription in mainstream TESOL methodology that tends to discourage the use of students' L1 in the classroom (for a discussion of how students' L1 can be capitalized on in an L2 classroom, see Lin, 1999), a Hong Kong society where the English-speaking communities and the Cantonese-speaking majority communities occupy different positions in the society and are socioculturally isolated from each other, a long-existing textbook and examination-driven school culture, a rigid school building with small, crowded, inflexible classrooms, a group of lively Cantonese-dominant youngsters, in whose lifeworld outside-school English does not play any significant role, and who do not find English interesting although they are aware of the fact that English is ultimately needed in the adult world (as expressed by a student interviewed by the researcher).

Determining when, where and how these forces might be re-articulated (Slack, 1996) becomes the difficult but not entirely impossible task of a critical researcher. In the above example it seems that we can mainly work on the long-range possibilities of re-shaping and re-articulating some of the forces, e.g., de-constructing the dominant notion that native English speakers make better English teachers, incorporating in teacher-education courses topics on understanding local students' sociocultural worlds and their practices of resistance and identities, excavating the material and sociocultural conditions and capitals required for progressive liberal educational reforms and demystifying cultural relativism-efforts that the authors of this paper have been striving to engage in through research, teaching, writing, community services and policy advocacy, working with students, school principals, parents, teachers and other educational researchers. In the second example below, we shall try to show how, sometimes, an immediate re-articulation of some of the forces can be possible.

\section{Example (2):}

\section{About the teacher and the researcher:}

In this example, we are going to look at the story of Tracy (pseudo name), a student-teacher working with the first author of this paper at the City University of Hong Kong. In the Autumn of 2001, Tracy was randomly assigned to a working 
class school to do her 5-week practicum (Practice Teaching) as part of the requirements for her B.A. (TESL) degree. Tracy also kept a diary of her Practice Teaching experience as part of her practicum work, which included both a teaching component and a self-reflection component. Tracy impressed the first author as an enthusiastic and energetic student and teacher with a genuine desire to help her students to not just improve their English proficiency but also develop an interest in learning English. Tracy and the first author have a good, trusting relationship. During her 5-week practicum, Tracy maintained continuous contact through e-mail and occasional meetings with the first author, who at that time served as her university tutor for Practice Teaching. At the end of the practicum, Tracy shared her experiences with the first author (the researcher) and gave permission to the researcher for citing her diary for research and educational purposes.

\section{About the school and the class:}

The school that Tracy was assigned to was a government secondary school located next to a working class public housing estate in the New Territories (comparable to Jennifer's school in Example (1) above). Tracy was responsible for taking all the English language lessons of class 2B (Secondary 2 or Grade 8 in the N. American System). There were 40 students in the class, half boys and half girls, aged around twelve to thirteen. According to her cooperating teacher (her practicum supervisor in the school, and the original English teacher of the class), class 2B was second best at Secondary 2 level in the school, where classes had been streamed according to their academic standards and learning attitudes. However, to Tracy's dismay, her first lesson with the class gave her a hard landing in a real classroom setting (i.e., as opposed to her previous micro-teaching experience in a simulated classroom setting at the university). Below are excerpts from her first journal (29/10/2001) as well as her $19^{\text {th }}$ journal $(27 / 11 / 2001)$ one month later (italics added):

\section{9/10/2001 Journal 1}

\section{Recap of the lesson}

- Write 5 sentences about one of their classmates.

- Students are put into groups of four.

- $\quad$ The four students in the group are numbered as S1, S2, S3 and S4.

- Read out the sentences to the group members and ask him/her to guess who this person is.

\section{Reflection}


Today I was very depressed. Nobody listened to me. I was not well prepared for these two lessons because my cooperating teacher said earlier that she needed both lessons to complete answer-checking ${ }^{1}$ with the class, and that I didn't need to take the lessons. However, in the last minute, she suddenly told me it was unnecessary and I could have the two lessons back. I had prepared a speaking activity and one writing activity for them, and it was too late for me to realize during the lessons that the class was not ready to do any tasks different from their textbook exercises.

In these two lessons, nobody listened to me. Maybe they did not understand their job or they did not know how to 'speak English' with their neighbors - they might never have had this experience before. I just asked them to read what they wrote to their neighbors but then the whole class lost control and started chatting with one another on non-lesson topics. I guess I have introduced a cooperative learning method, which, however, seemed to be unfamiliar to them. They had a big chance to fool around and talk and become off-task. I have never thought about the students would not even know how to read the sentences to their neighbours. Their speaking did not involve simultaneous thinking. In no more than ten minutes, the class turned into chaos. I felt helpless in the classroom and suddenly I opened my mouth and said something which was from the bottom of my heart to the students. My English was not that good in the secondary school especially my spoken English. I told them I could not say a word in the oral examination practice at Secondary 4. I could not say a complete sentence when I was a year one student at the City University. I told them I have really put great efforts in improving my speaking ever since. I trained myself not to read the Chinese subtitles of the English TV programmes. I forced myself to read South China Morning Post even tough I disgusted reading English newspapers. I talked to myself using the dialogues from English TV dramas. I told them that they could have all spoken good English if they would treasure the learning opportunities they now have. Then the class turned to silence and everyone was looking at me. I spent more than fifteen minutes to say those words and I said them in Cantonese. After that, the students started to the speaking task I had assigned and then the lesson ended.

I wanted to cry at that time but I held back the tears. I had thought about not

\footnotetext{
1 Answer-checking is a typical classroom practice, especially in working class schools, in Hong Kong. Typically, students are assigned some textbook exercises to do quietly on their own or at home, and then afterwards, the teacher uses a whole-class IRF discourse format to elicit answers to textbook questions from students, and give students the correct model answers if students' answers are not correct. See Lin , 1999 for critical analyses of these classroom practices.
} 
becoming a teacher after my graduation. However, when I settled down and pulled myself together, I said to myself it was just the first day. Progress could be made and I should do my best to solve the problems. Then I started to plan for the next day's lessons because I had to change my lesson plans.

I was shocked when I looked back at the lessons. I introduced a cooperative learning method to a class who did not have much pair work experience before. No wonder they had no idea what to do and just played with their classmates during the task time. I was definitely not prepared well for this task and I expected they could all understand the task. Angel told me that the students had the reason to be off-task because they did not know how to start the task; they did not have any experience of doing pair work in the past. I have to admit that I planned the lessons wrongly. I tried the task out in a small group of elite students in a band 2 class $^{2}$ successfully and I assumed that there should not be any problem when I tried it out in a real classroom setting.

27/11/2001 Journal 19

I have so much to say. Today was really a great challenge. Last week I told them that they had to stay after school if they did not do their projects and I would teach them how to do it. So I asked who had not started doing the project yet. More than half of them put up their hands. ... Later, I told them that the reason for carrying out the project was that in doing the project they could have the chance to use English in a meaningful context. I told them that two boys from their class had completed an English interview yesterday, and they had never thought they could do it before. Then the class seemed to be more understanding. I had to admit that I spent so little time on teaching them how to do the project but I had given them everything they needed in advance. They said they knew how to do but they just forgot everything afterwards. I felt so bad and disappointed I doubt that whether I am asking them to do something that they were incapable of because of my inadequate input. ...

In fact, one group of girls had submitted their project and it really surprised me. Their work was so fantastic. I think I should be happy with this piece of great work. ...

Back to my teaching, I played a song to them and asked them to fill in the blanks in

\footnotetext{
2 That was the simulated classroom setting that the student-teacher designed for her micro-teaching practice at the university.
} 
the lyrics. They did not do the task during the first time I played the song. I told them the reason behind this task after playing the song. I told them I wanted to help them develop an interest in listening to English songs. Moreover, they could learn English from the media and it was more interesting. After I had said these words, they started trying to capture the words during the second time I played the song. Most of them were able to fill in two-three blanks. At that time, I realized how important it was to explain to my students the objectives of the tasks. Sometimes students do not engage in the task possibly because they do not know what to do or why they have to do it. ...

I waited for the class outside the music room because I had to prevent anyone of them leaving the school. Today I said to them that they would have an 'after class meeting' for the project. In fact, it was the input session. Students' response was unexpected. When they knew that the marks for the project would be counted in their coursework section of the year (in fact, my cooperating teacher had never said yes to it), the girls suddenly became concerned about the project very much. They asked how they could get high marks for their project. I photocopied a project done by their classmates which had been the first submitted to me. It was effective to motivate them to put more efforts in the project. Some boys just wanted to get a pass. I let them leave at 3:45 pm. So actually it was not a detention.

\section{Analysis and Discussion:}

From the above diary excerpts, we see a student-teacher armed with progressive liberal pedagogies that she had learnt from the university going into a non-middle class school setting trying to implement these pedagogies (e.g., cooperative learning tasks, pair and group work, integrated language projects). However, her students had been used to the traditional learning and teaching approaches adopted by the original teacher (the cooperating teacher) and the school, where teachers mostly did textbook exercises and answer-checking with students and where project work had never been done before and project marks would not count as part of the coursework marks. The progressive liberal pedagogies that the student-teacher had learnt, however, had not prepared her for what to do when students did not respond well to these pedagogies, because these pedagogies, as we understand (see discussion in Section 2 above), have originally arisen from middle class conditions and have not built into their canons ways of adapting them to non-middle class conditions where both the right attitudes and capitals to benefit from these pedagogies are missing. The student-teacher had also chosen a middle class setting (a band 2 class $^{3}$ ) as the

\footnotetext{
${ }^{3}$ In Hong Kong, schools are classified into different bands according to their academic standards.
} 
simulated classroom when she did her micro-teaching practice at the university ${ }^{4}$.

The student-teacher (and we as teacher-educators and classroom researchers, too) are confronted with an important, ethical decision: should the teacher press on with the progressive liberal pedagogies, or should she give up and revert to the traditional teaching approaches which the students were apparently more accustomed to? The normative order of progressive liberalism would have us encourage the teacher to press on with the more "progressive" pedagogies although these pedagogies in general offer little guidance to teachers who encounter students who do not respond well to these pedagogies (e.g., Jennifer in Example (1) and Tracy in Example (2) above). On the other hand, the normative order of cultural relativism would come to our rescue and have us encourage the teacher to revert to the traditional teaching style that the students respond well to: the textbook exercise and answer-checking approaches. In Example (1) above, we see that the native English teacher had chosen the latter course of action given her perception that the former was not a feasible pedagogy in view of her students' deep-rooted learning style (i.e., they would be quiet and on-task only when they were doing a textbook exercise or grammar worksheet).

In the diary excerpts of Tracy in Example (2) above, however, we see a resilient attempt on her part to explain with all sincerity to her students why and how the tasks and projects were useful to them, through sharing her own learning experiences with the students (e.g., she could not speak one complete English sentence in her own oral examination at Secondary 4 because she had not had any chance to do any pair speaking in her previous learning). She achieved some success in persuading her students about the benefits of the tasks. Parallel to this effort, she also put in a lot of extra hours working with individual and small groups of students after class, giving them additional support and encouragement to help them gain a sense of achievement with their project work (e.g., she spent hours coaching two boys in asking some English interview questions, which they later used successfully by themselves in their interview project, and the boys were both surprised and happy to find that they could actually do it - a more detailed description of this incident was found in another journal entry). Tracy also made use of the students' concern for their marks to motivate them to do the projects by telling a white lie (that the project marks will

Band 2 at that time was an above-average band.

${ }^{4}$ The first author must also admit part of the responsibility for this inadequate preparation.

Student-teachers were given freedom to choose the type of setting as their simulated classroom to do their micro-teaching practice, and most students somehow prefer choosing good banding settings. 
count in their coursework marks).

In a way, through giving extra attention and support to her students outside class, she partially compensated for the lack of middle class attitudes and capitals on the part of her students for responding well to and benefiting from progressive pedagogies, which in the long run will give them the proficiency needed to compete with the middle class graduates in the society (e.g., in the public oral exams or in the university). Tracy, drawing on her own English learning experiences, knows just too well how far behind in English she would have been if she had just accepted the traditional English teaching and learning methods she herself was subjected to when she was a secondary school student. She, therefore, went to lengths to both help her students to realize the benefits of these approaches and to provide them with the necessary capitals to benefit from such approaches while also adapting them to suit her students.

Through the agency of Tracy, the English learning context of the students has been partially re-shaped. While Tracy could not totally change the examination system and the textbook-exercise-driven curriculum and school culture, she introduced some alternative elements into the setting, which have initiated some changes among her students. At the end of her 5-week practicum, her students (including a boy who said who hated her in the beginning days) gathered around her, asking her to come back to teach them in the future, and telling her that they had become more interested and confident in learning English (a description of this is found in her last journal entry). By re-articulating some of the forces which formed the context in which her students were situated, Tracy was partially successful in bringing about some situated change and transformation, as evidenced in the more positive English learning attitudes of her students and in their development of a confident, competent English language learner identity.

\section{Towards Critical Postmodernist, Sociohistorically Situated Perspectives in Classroom Studies}

Modernism produces many of our theoretical and practical traps by their universal truth and knowledge claims (or grand narratives) detached or abstracted from concrete sociohistorical conditions. For instance, progressive liberalism and cultural relativism have their essentializing and absolutizing tendencies, and both share a lack of attention to concrete, local, sociohistorical contexts where classroom participants are situated (see discussion in Section 2 above). Critical reproduction theories, however, also run the risk of falling into the trap of economic and class determinism 
and reductionism, which are also products of modernist thinking (see discussion in Section 3 above). Radical postmodernism, while strong in deconstructing the universal truth claims and grand narratives of modernism, runs the risk of losing all normative, ethical frameworks which are needed if one is to do practical, critical work in concrete, local sites (Luke, 2002a, 2002b). What we need at this historical conjuncture seems to be a "critical postmodernism" which does not reduce to radical postmodernist relativism on the one hand, and which does not subscribe to modernist grand narratives on the other. For lack of space in this article to do a full-fletched discussion of critical postmodernism, the following quotes are meant to arouse the reader's further interest in the topic:

" ... the polarizing polemics of the radical postmodernists who once dominated the discussion have given way to a new 'critical postmodernism'..." (Gabardi, 2001)

"Critical postmodern is the nexus of critical theory, postcolonialism, critical pedagogy and postmodern theory (See Tamara, Journal of Critical Postmodern Organization Science).”

(From: http://cbae.nmsu.edu/ dboje/pages/what is critical_postmodern.htm)

In our understanding, critical postmodernist perspectives emphasize situated studies of concrete, local, sociohistorical contexts and lived experiences, based on which situated, local, critical projects can be conceptualized and pursued by the local participants. While rejecting grand narratives and grand projects of universal emancipation which characterize some versions of modernist critical theory, critical postmodernism, nevertheless, does not reduce to radical relativism, and does not lose sight of the concrete struggles of local social actors situated in specific sociohistorical contexts. As Jay Lemke puts it,

What critical postmodernism means, to me, is a critique of ALL of modernism, and primarily a critique of the founding assumptions of modern European culture (i.e. from Renaissance-Enlightenment onwards). Post-colonial critiques of this sort have the virtue of coming from at least partially outside the tradition they critique, and the virtues of both speaking to non-European peoples and speaking about relatively practical matters of lived experience and conflicts with Eurocultural institutions and their values." (Jay Lemke, personal communication, February 10, 2002). 
This paper has been written as an attempt to critically analyse two kinds of Angloand Euro-based modernist normative orders (progressive liberalism and cultural relativism), which have dominated much of pedagogical and research practices in mainstream TESOL and applied linguistics. In proposing critical postmodernist, sociohistorically situated perspectives and drawing on the theory and method of articulation in doing classroom studies, we aim at departing from the modernist essentialism of progressive liberalism and cultural relativism on the one hand, and the modernist determinism and reductionism of reproduction theories on the other. As part of a continuous effort in exploring new conceptual and research spaces in language education, we hope that our paper might arouse more critical discussion on the topic of how one can still pursue critical projects and engage with the ethical responsibilities inherent in doing education research in a postmodernist era where critical work comes with no guarantees and no grand narratives.

\section{References}

Apple, M. W. (1999). Power, meaning, and identity: Essays in critical educational studies. New York: Peter Lang.

Block, D., \& Cameron, D. (Eds.) (2002). Globalization and language teaching. London: Routledge.

Canagarajah, A. S. (1993). Critical ethnography of a Sri Lankan classroom: Ambiguities in student opposition to reproduction through ESOL. TESOL Quarterly, 27(4), pp. 601-626.

Canagarajah, A. S. (1999). Resisting linguistic imperialism in English teaching. Oxford: Oxford University Press.

Chick, J. K. (1996). Safe talk: Collusion in apartheid education. In Coleman, H. (Ed.), Society and the language classroom (21-39). Cambridge: Cambridge University Press.

Collins, J. (1996). Socialization to text: Structure and contradiction in schooled literacy. In Silverstein, M., \& Urban, G. (Eds.), Natural histories of discourse (pp. 203-228). Chicago: The University of Chicago Press.

Dewey, J. (1938). Experience and education. New York: Macmillan.

Foucault, M. (1981). Questions of method: An interview with Michel Foucault. Ideology and Consciousness, 207, pp. 18-23.

Gabardi, W. (2001). Negotiating postmodernism. Minneapolis, Minn.: University of Minnesota Press. 
Gould, C. C. (2001). Two concepts of universality and the problem of cultural relativism. In C. C. Gould, \& P. Pasquino (Eds.), Cultural identity and the nation-state (pp. 67-84). Lanham: Rowman \& Littlefield Publishers.

Grossberg, L. (1992). We gotta get out of this place: Popular conservatism and postmodern culture. New York: Routledge.

Hall, S. (1996). The problem of ideology: Marxism without guarantees. In D. Moley, \& K-H. Chen (Eds.), Stuart Hall: Critical dialogues in cultural studies (pp. 25-46). London: Routledge.

Hall, S. (1977). Rethinking the "base-and-superstructure" metaphor. In J. Bloomfield (Ed.), Papers on class, hegemony and party (pp. 43-72). London: Lawrence \& Wishart.

Heap, J. L. (1990). Applied ethnomethodology: Looking for the local rationality of reading activities. Human Studies, 13, pp. 39-72.

Heap, J. L. (1997). Conversation analysis methods in researching language and education. In N. H. Hornberger, \& D. Corson (Eds.), Encyclopedia of Language and Education (Vol. 8, pp. 217-255). The Netherlands: Kluwer Academic Publishers.

Heller, M., \& Martin-Jones, M. (Eds.) (2001). Voices of authority: Education and linguistic difference. Westport, Connecticut: Ablex.

Jackson, P. W. (1990). Introduction. In J. Dewey, The school and society and the child and the curriculum (pp. ix-xvii). Chicago: The University of Chicago Press.

Kubota, R. (2001). Discursive construction of the images of U.S. classrooms. TESOL Quarterly, 35(1), 9-38.

Kumaravadivelu, B. (1999). Critical classroom discourse analysis. TESOL Quarterly, 33(3), pp. 453-484.

Li, X. (1995). Gender inequality in China and cultural relativism. In M. C. Nussbaum and J. Glover (Eds.), Women, culture, and development (pp. 407-425). Oxford: Clarendon Press.

Lin, A. M. Y. (1996). Bilingualism or linguistic segregation? Symbolic domination, resistance, and code-switching in Hong Kong schools. Linguistics and Education, 8(1), 49-84.

Lin, A. M. Y. (1997). Bilingual Education in Hong Kong. In J. Cummins, \& D. Corson (Eds.). Encyclopedia of Language and Education (Vol. 5, pp. 281-289). The Netherlands: Kluwer Academic Publishers.

Lin, A. M. Y. (1999). Doing-English-lessons in the reproduction or transformation of social worlds? TESOL Quarterly, 33(3), pp. 393-412.

Luke, A. (2002a). Beyond science and ideology critique: Developments in critical discourse analysis. In M. McGroarty (Ed.), Annual Review of Applied 
Linguistics, vol. 22, pp. 96-110.

Luke, A. (2002b). Curriculum, ethics, metanarrative: Teaching and learning beyond the nation. Curriculum Perspectives.

Moll, L. C., \& Dworin, J. E. (1996). Biliteracy development in classroom: Social dynamics and cultural possibilities. In Hicks, D. (Ed.), Discourse, learning, and schooling (pp. 221-246). Cambridge: Cambridge University Press.

O’Connor, M. C., \& Michaels, S. (1996). Shifting participant frameworks: Orchestrating thinking practices in group discussion. In Hicks, D. (Ed.), Discourse, learning, and schooling (pp. 63-103). Cambridge: Cambridge University Press.

Pennycook, A. (2001). Critical applied linguistics. Mahwah, New Jersey: Lawrence Erlbaum.

Rampton, B. (1995a). Crossing: Language and ethnicity among adolescents. London: Longman.

Rampton, B. (1995b). Politics and change in research in applied linguistics. Applied Linguistics, 16, pp. 233-256.

Richardson, L. (1997). Fields of play (Constructing an academic life). New Brunswick, New Jersey: Rutgers University Press.

Said, E. (1978). Orientalism. New York: Pantheon Books.

Slack, J. D. (1996). The theory and method of articulation in cultural studies. In D. Moley, \& K-H. Chen (Eds.), Stuart Hall: Critical dialogues in cultural studies (pp. 112-127). London: Routledge.

\section{Acknowledgements:}

The authors are indebted to John Erni, Jay Lemke and Allan Luke for discussing with them some key concepts in this paper. Special thanks go to the editors and two anonymous reviewers for their useful comments and suggestions. 